\title{
Optical and $\mathrm{NH}_{3}$ Gas Sensing Properties of Hole-Transport Layers Based on PEDOT: PSS Incorporated with $\mathrm{Nano}^{-\mathrm{TiO}_{2}}$
}

\author{
Lam Minh Long ${ }^{1}$, Tran Quang Trung ${ }^{2}$, Vo-Van Truong ${ }^{3}$, Nguyen Nang Dinh ${ }^{1}$ \\ ${ }^{1}$ University of Engineering and Technology, VNU in Hanoi, Hanoi, Vietnam \\ ${ }^{2}$ University of Natural Science, VNU in HoChiMinh City, Ho Chi Minh City, Vietnam \\ ${ }^{3}$ Department of Physics, Concordia University, Montreal, Canada \\ Email:dinhnn@vnu.edu.vn
}

How to cite this paper: Long, L.M., Trung, T.Q., Truong, V.-V. and Dinh, N.N. (2017) Optical and $\mathrm{NH}_{3}$ Gas Sensing Properties of Hole-Transport Layers Based on PEDOT: PSS Incorporated with Nano- $\mathrm{TiO}_{2}$. Materials Sciences and Applications, 8, 663-672. https://doi.org/10.4236/msa.2017.89047

Received: July 20, 2017

Accepted: August 18, 2017

Published: August 21, 2017

Copyright $\odot 2017$ by authors and Scientific Research Publishing Inc. This work is licensed under the Creative Commons Attribution International License (CC BY 4.0). http://creativecommons.org/licenses/by/4.0/

\begin{abstract}
Poly(3,4-ethylenedioxythiophene):poly(styrenesulfonate) incorporated with nanocrystalline $\mathrm{TiO}_{2}$ powder (PEDOT:PSS $+n c-\mathrm{TiO}_{2}$ ) films were prepared by spin-coating technique. SEM surface morphology, UV-Vis spectra and $\mathrm{NH}_{3}$ gas sensing of were studied. Results showed that the PEDOT:PSS+nc- $\mathrm{TiO}_{2}$ film with a content of $9.0 \mathrm{wt} \%$ of $\mathrm{TiO}_{2}$ is most suitable for both the hole transport layer and the $\mathrm{NH}_{3}$ sensing. The responding time of the sensor made from this composite film reached a value as fast as $20 \mathrm{~s}$. The rapid responsiveness to $\mathrm{NH}_{3}$ gas was attributed to the efficient movement of holes as the major charge carriers in PEDOT:PSS $+\mathrm{nc}-\mathrm{TiO}_{2}$ composite films. Useful applications in organic electronic devices like light emitting diodes and gas thin film sensors can be envisaged.
\end{abstract}

\section{Keywords}

PEDOT:PSS + nc- $-\mathrm{TiO}_{2}$ Composite, UV-Vis Spectra, J-V Characteristic, Thermal Sensing Property, Hole Transport Layer, $\mathrm{NH}_{3}$ Gas Sensing

\section{Introduction}

Poly(3,4-ethylenedioxythiophene):poly(styrenesulfonate) (PEDOT:PSS) is a conjugate polymer that can be easily prepared in thin film form. PEDOT:PSS films have a high transmission in the visible region, a high conductivity of $80 \mathrm{~S} / \mathrm{cm}$ [1] [2] [3], and a particularly good thermal stability [4] that is why PEDOT:PSS is used as the hole transport layer in many optoelectronic devices such as organic light emitting diodes (OLED), organic solar cell (OSC), electrochromic windows, 
etc. [5] [6] [7] [8]. PEDOT:PSS possesses also a highly valuable property: when adsorbed by various gases, its electrical conductivity changes considerably. Thus PEDOT:PSS can be used for the functional materials in the gases sensors [9]. Recently, Olenych et al. [10] used hybrid composites based on PEDOT: PSSporous silicon-CNT for preparation and characterization of humidity sensors. Various nanocomposite films consisting of conducting polymers mixed with carbon nanotubes (CNTs) as an active material have been prepared for application in gas thin film sensors for detecting the adsorption of gas molecules such as $\mathrm{CO}$ [11], $\mathrm{NH}_{3}$ [12] and vapors of organic solvents or water [13] [14]. Xing et al. [15] reported that the formation of a nanometer-scale chemically responsive junction (CRJ) within a silver nanowire (AgNW) strongly affected the sensing properties of nanocomposites. The proposed mechanism of the resistance response for a CRJ, supported by temperature-dependent measurements of the conductivity for CRJs and density functional theory calculations, is that semiconducting p-type $\operatorname{Ag}_{\mathrm{x}} \mathrm{O}$ is formed within the CRJ and the binding of molecules to this $\mathrm{Ag}_{\mathrm{x}} \mathrm{O}$ modulates its electrical resistance. We have shown by our experients that with embedding nanocrystalline $\mathrm{TiO}_{2}\left(\mathrm{nc}-\mathrm{TiO}_{2}\right)$ particles in PEDOT:PSS, the performance parameters of some electronic devices like OLED and OSC were considerably improved [16]. The improvement was attributed to the presence of the heterojunctions of PEDOT:PSS/MEH-PPV (for OLEDs) and PEDOT:PSS/P3HT (for P3HT) in the devices.

Thus in the hope to enhance the sensitivity of the $\mathrm{NH}_{3}$ sensor, PEDOT:PSS + nc- $\mathrm{TiO}_{2}$ composite films were prepared and characterized using $\mathrm{UV}-\mathrm{V}$ is and current-voltage measurements. The $\mathrm{NH}_{3}$ gas sensing vs. nc- $\mathrm{TiO}_{2}$ concentration embedded in PEDOT:PSS has been also studied.

\section{Experiment}

For preparing an initial solution of PEDOT:PSS, the pure PEDOT powder was dissolved in a largely diluted PSS by a volume ratio of PEDOT:PSS equal to 1:10. To get nanocomposite of PEDOT:PSS with nanocrystalline $\mathrm{TiO}_{2}$ (nc- $\left.\mathrm{TiO}_{2}\right), \mathrm{TiO}_{2}$ nanopowder with average size of $5 \mathrm{~nm}$ was embedded in this solution according to a weight ratio $\mathrm{TiO}_{2} / \mathrm{PEDOT}$-PSS of 0.05 to $0.07,0.09$ and 0.11 (or 5.0 to 7.0, 9.0 and $11.0 \mathrm{wt} \%$ ), further referred to as PECT-1, PECT-2, PECT-3 and PECT-4 sample, respectively. To obtain a homogenous dispersion of $\mathrm{nc}^{-\mathrm{TiO}_{2}}$ in polymer, the solutions were mixed for 8 hours by using magnetic stirring. These liquid composites were then used for spin-coating. The conditions for spin-coating were as follows: a delay time of $90 \mathrm{~s}$, a rest time of $20 \mathrm{~s}$, a spin speed of $1500 \mathrm{rpm}$, an acceleration of $500 \mathrm{rpm}$ and finally a drying time of $3 \mathrm{~min}$. The Corning-247 glass pieces with $2 \mathrm{~cm} \times 3 \mathrm{~cm}$ in size was used as substrates for optical characterization, and ITO-coated glass substrates were used for the anode in OLEDs. Both the glass and ITO-coated glass substrates used for spincoating nanocomposite films were ultrasonically cleaned in distilled water, followed by cleaning in ethanol and acetone. Preparation of OLEDs for density current-voltage (J-V) 
measurements was carried-out following the process that was described in [16], herein the conjugate polymer of poly [2-methoxy-5-(2'-ethyl-hexyloxy)-1,4phenylene vinylene] (MEH-PPV) was used as the electroluminescent layer, PECT films-as the hole transport layer (HTL) and aluminum coating-as the cathode. For preparing thin film sensors, the PEDOT:PSS $+\mathrm{nc}-\mathrm{TiO}_{2}$ solutions were spin-coated onto glass substrates which were coated by two silver planar electrode arrays with a square of $5 \times 5 \mathrm{~mm}$ in size. The two electrodes were separated from each other by a distance of $5 \mathrm{~mm}$. To dry the films, the samples were put in a flow of dried gaseous nitrogen for 8 hours. For the solidification without involving solvents, the film samples were annealed at $120^{\circ} \mathrm{C}$ for $8 \mathrm{~h}$ in a "SPT-200" vacuum drier. The thickness of the PECT films was controlled at an average value of $450 \mathrm{~nm}$. All the samples were put in a fore vacuum box until the measurements.

The surface morphology of samples was characterized by using a NT-MDT Atomic Force Microscope operating in a tunnel current mode. The compositional characterization of the PEDOT-PSS films was done through Fourier Transform Infrared Spectroscopy (FTIR) on a BRUKER TENSOR-27 spectrometer. Ultraviolet-Visible absorption spectra (UV-Vis) were carried-out by using a JASCO V570 spectrophotometer and J-V characteristics were measured on an Auto-Lab Potentiostat PGS-30.

\section{Results and Discussion}

The surface of nanocomposite samples was examined by AFM techniques. Figure 1 shows AFM images of a pure PEDOT:PSS and a PECT with an embedding of $9.0 \mathrm{wt} \% \mathrm{nc}^{-\mathrm{TiO}_{2}}$. In the PEDOT:PSS sample there is a lot nanopores, whereas in the composite sample considered, a distribution of completely dispersive $\mathrm{TiO}_{2}$ nanoparticles can be seen. Moreover, in the composite film the nanopores did not appear, instead $\mathrm{nc}-\mathrm{TiO}_{2}$ particles were formed (as seen in Figure 1 for examples, pores 1 and 2 (Figure 1(a)) were replaced by particles 1' and 2' (Figure 1(b))). This AFM micrograph also shows that the PEDOT:PSS + nc-TiO 2 composite film contained numerous $\mathrm{TiO}_{2} / \mathrm{PEDOT}$-PSS nano-heterojunctions.

Figure 2 shows the FTIR spectra obtained for a PEDOT:PSS film sample. Signals from 1527 to $1368 \mathrm{~cm}^{-1}$ are associated with the $\mathrm{C}=\mathrm{C}$ bonds, peaks at 985 , 844 , and $688 \mathrm{~cm}^{-1}$ can be attributed to the C-S interaction in the thiophene ring, and peaks 1228 through $1051 \mathrm{~cm}^{-1}$ correspond to the ethylenedioxy group. There are 10 characteristic peaks signed with a red star belong to PEDOT:PSS as reported in [17]. Figure 3 shows the optical absorption spectra (UV-Vis) of the PEDOT:PSS and PECT films. The absorbance of the films decreased with increasing $\mathrm{TiO}_{2}$ content embedded in the polymer. The decrease in absorption spectra can be explained due to i) a large bandgap of $\mathrm{nc}^{-\mathrm{TiO}_{2}}$ and ii) a stronger scattering effect of the light illuminating to the composite films.

The UV-Vis data in Figure 3 can be used to estimate the energy band gap, $E_{g}$, of the samples by using the following expression [18]. 


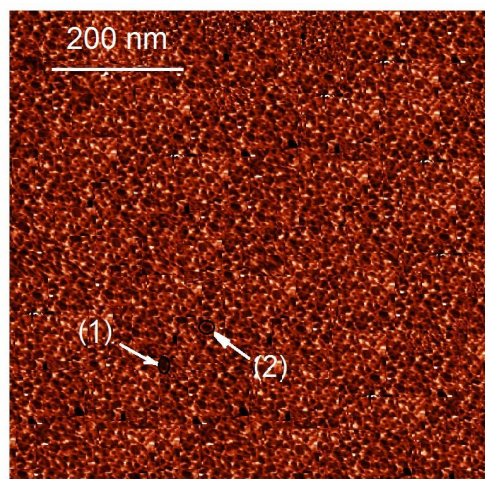

(a)

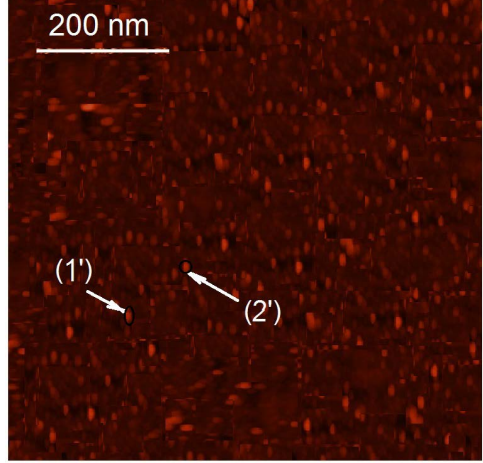

(b)

Figure 1. AFM images of a pure PEDOT:PSS (a) and a PEDOT:PSS+nc- $\mathrm{TiO}_{2}(9.0 \mathrm{wt} \%)$ composite film (b).

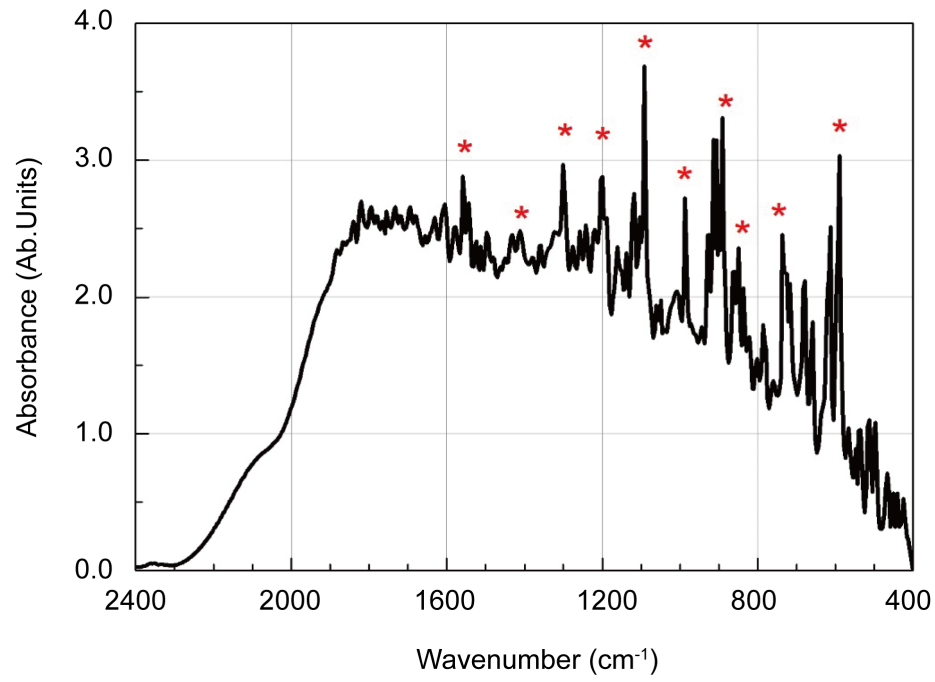

Figure 2. FTIR spectrum of a PEDOT:PSS film.

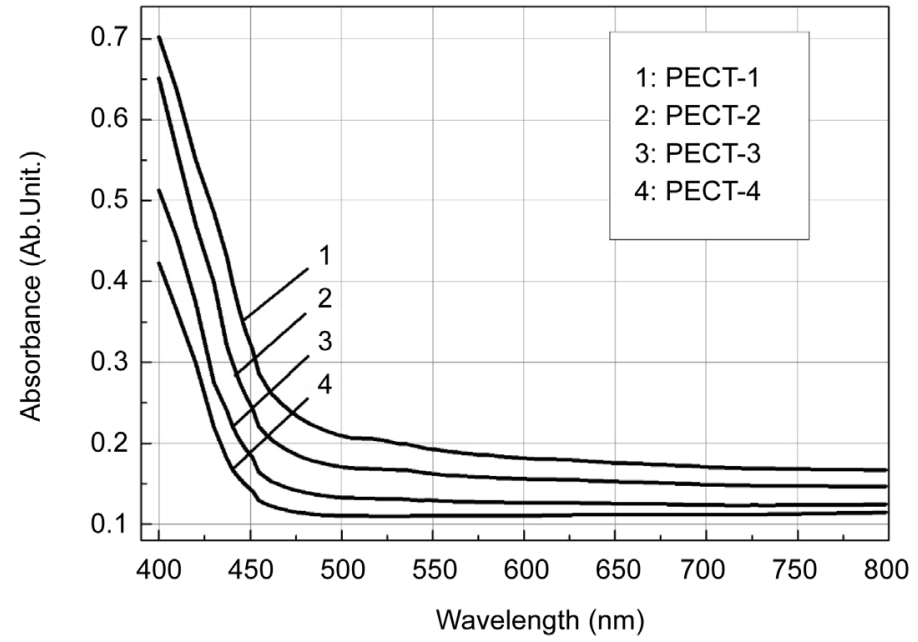

Figure 3. UV-Vis absorption spectra of the PECT thin films incorporated with nc- $\mathrm{TiO}_{2}$ : $5.0 \mathrm{wt} \%$ (curve “1”), $7.0 \mathrm{wt} \%$ (curve "2"), $9.0 \mathrm{wt} \%$ (curve “3”) and $11.0 \mathrm{wt} \%$ (curve "4") of nc- $\mathrm{TiO}_{2}$. 


$$
\alpha h v=A\left(h v-E_{g}\right)^{n}
$$

where $h$ is Planck's constant, $v$ is the frequency of the incident UV-Vis radiation, $\mathrm{A}$ is a constant and $\mathrm{n}$ is $1 / 2$ for direct band semiconductors and 2 for indirect band gap semiconductors. As expected, best fits were obtained for $n=2$ (indirect band).

A graph is plotted between the square of $(\alpha h v)$ and $h v$ (as abscissa), and a straight line is obtained. From the extrapolation of the straight line to $(\alpha h v)^{1 / 2}=$ 0 axis, one can determine the bandgap of the investigated sample. Thus from our experiments, the energy gap $\left(E_{g}\right)$ of two samples (namely PECT-1 and PECT-3) were found to be of approximately $2.50 \mathrm{eV}$ and $2.57 \mathrm{eV}$, respectively (Figure 4). For PECT-2 and PECT-4 similar results were obtained, and their $E_{g}$ values were found to be of 2.52 and $2.54 \mathrm{eV}$, respectively. The value of the bandgap of nanocomposites is a little larger than that for the pure PEDOT-PSS film prepared by electrochemical polymerization [19]. In addition, the effect of widening in the

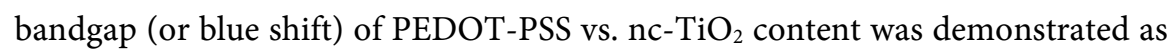
shown in Table 1 . This is quite similar to the reported blue shift that was observed for $\mathrm{MEH}-\mathrm{PPV}+\mathrm{nc}-\mathrm{TiO}_{2}$ [20] or for $\mathrm{PPV}+\mathrm{nc}-\mathrm{SiO}_{2}$, where the blue shift was explained by a reduction in the polymer conjugation chain length due to the presence of inorganic nanoparticles in polymers [21].

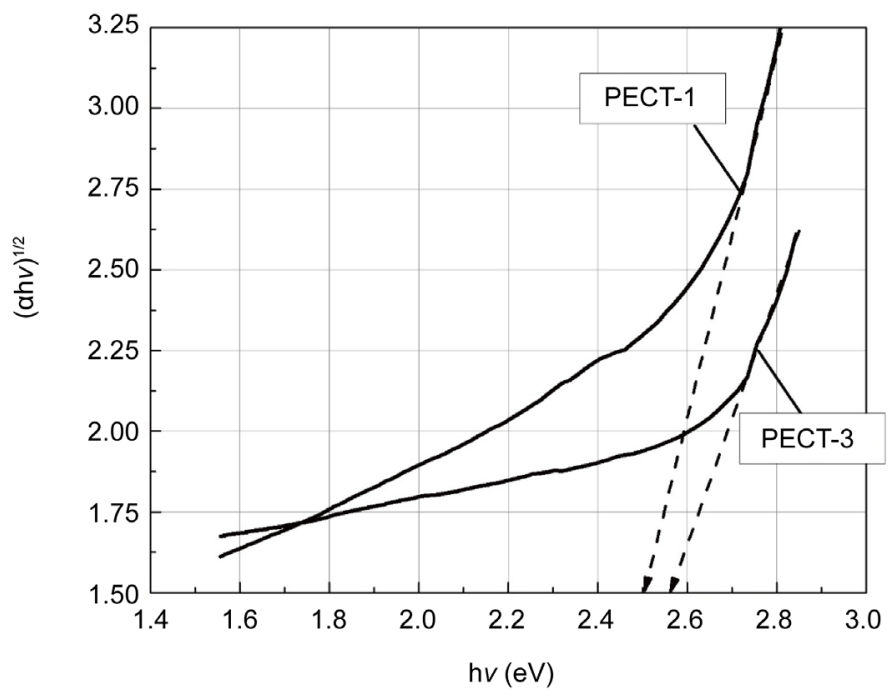

Figure 4. Plots of $(\alpha h v)^{1 / 2}$ dependence on photon energy $(h v)$ for determining $E_{g}$ of the PECT-1 and PECT-3 samples.

Table 1 . The widening in $E_{g}$ of conjugate polymer (PEDOT:PSS) vs. $\mathrm{TiO}_{2}$ content.

\begin{tabular}{ccc}
\hline Samples & $\mathrm{TiO}_{2}$ content $(\mathrm{wt} \%)$ & $E_{g}(\mathrm{eV})$ \\
\hline PECT-1 & 5.0 & 2.50 \\
PECT-2 & 7.0 & 2.52 \\
PECT-3 & 9.0 & 2.54 \\
PECT-4 & 11.0 & 2.57 \\
\hline
\end{tabular}


It is known that PEDOT:PSS can be considered as a p-type organic semiconductor [22], where holes play the role of major charge carriers. This is why PEDOT:PSS thin film is often used for hole transport layer (HTL) in OLEDs [23] [24] [25] [26]. To better understand the effect of hole transport in nanocomposite films, we measured the J-V characteristics of the devices made from different layers, such as ITO/MEH-PPV/PECT-1/Al, ITO/MEH-PPV/PECT-2/Al, ITO/ $\mathrm{MEH}-\mathrm{PPV} / \mathrm{PECT}-3 / \mathrm{Al}$ and ITO/MEH-PPV/PECT-4/Al, abbreviated as DMP-1, DMP-2, DMP-3 and DMP-4, respectively. The measurement data for J-V characteristics of these devices were plotted as shown in Figure 5.

From Figure 5 one can notice the following: i) $\mathrm{TiO}_{2}$ nanoparticles embedded in PEDOT:PSS used as HTL favors the hole injection from ITO into the organic layer deposited on the HTL, resulting in an enhancement of the J-V characteristics. Thus the turn-on voltage decreased from 1.80 to $1.42,1.32$ and $1.10 \mathrm{~V}$, respectively for devices DMP-1, DMP-2, DMP-4 and DMP-3, where J-V characteristic of DMP-3 device (with $\mathrm{nc}^{-\mathrm{TiO}_{2}}$ content of $9.0 \mathrm{wt} \%$ ) exhibits the best one; ii) The effect of the HTL on the enhancement of the J-V characteristics was well demonstrated, associated with the equalization process of injection rates of holes and electrons [27]. The reason why the nanoparticles can improve the device performance was recently discussed, when we reported the role of the surface morphology of the HTL layer in the composites [23]. With spinning process in the spin-coating technique, the nanopores can be filled-up by strong electrostatic forces, consequently eliminating the pores acting as big traps for charge carriers in polymers, thus more charge carriers (i.e. holes and electrons) can reach the anode and the cathode of the devices.

To test the gas sensitivity of the sensors made from PECT composites, the samples were placed in a chamber and device electrodes were connected to elec-

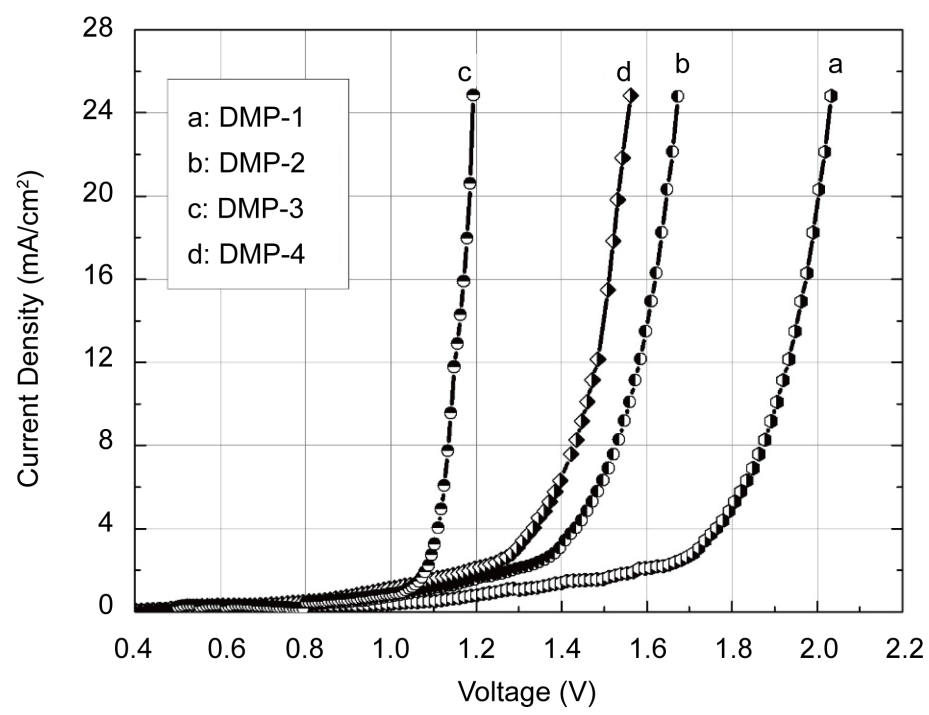

Figure 5. J-V characteristics of the PECT samples with different contents of $\mathrm{nc}^{-\mathrm{TiO}_{2}}$ from $5.0 \mathrm{wt} \%$ (curve "a") to $7.0 \mathrm{wt} \%$ (curve "b"), $9.0 \mathrm{wt} \%$ (curve "c") and $11.0 \mathrm{wt} \%$ (curve "d"). 
trical feedthroughs. For example, for monitoring $\mathrm{NH}_{3}$ gas, the best hole transport film (namely sample PECT-3) was put in a testing chamber of $10 \mathrm{dm}^{3}$ in volume. By using "EPA-2TH" profilometer (USA) a100 ppm (in concentration) $\mathrm{NH}_{3}$ gas value was chosen for monitoring. The adsorption process was controlled by insertion of measuring $\mathrm{NH}_{3}$ gas and the desorption process was done by extraction of the gas followed by insertion of dry gaseous Ar. To characterize the sensing performance of the PECT composite films used for the sensors, a sensitivity $(\eta)$ of the devices was introduced. It is determined by following equation:

$$
\eta=\frac{R-R_{O}}{R_{O}}(\%)
$$

where $R_{o}$ is the initial resistance of the sensor, and $R$ - the resistance of the sensor after the $\mathrm{NH}_{3}$ gas adsorption.

Typical $\mathrm{NH}_{3}$ gas sensing data for two sensors, namely PEC- 1 and PECT-3 are plotted in Figure 6. The sensing curves of the PECT-2 and PECT-4 lay between PEC-1 and PECT-3 curves, but for clear observation they were not inserted in Figure 6. From Figure 6, it is seen that with adsorption of $\mathrm{NH}_{3}$ gas the resistance of the PECT-3 sample increased. The sensitivity of the sensors increased from about $6 \%$ (for PECT-1) to $10 \%$ (for PECT-3). The responding time of the sensing shortened from $40 \mathrm{~s}$ to $32 \mathrm{~s}, 26 \mathrm{~s}$ and $20 \mathrm{~s}$, respectively for PECT-1, PECT-2, PECT-4 and PECT-3 sensors (see gray-marked parts in Figure 6). For the PECT-3 sensor, the resistance of the PECT-3 film quickly recovered to baseline when exposed to air (i.e. desorption of the gas). Indeed, the recovery time of the sensor was estimated as 80 s. This would imply that the electrons generated from the $\mathrm{NH}_{3}$ adsorption process in the sensor surface eliminated a part of holes in PEDOT:PSS with results similar to those reported in [9].

The fast responding time of the sensing can be attributed to the efficient movement of the holes in the nanocomposite-based hole transport layer, which

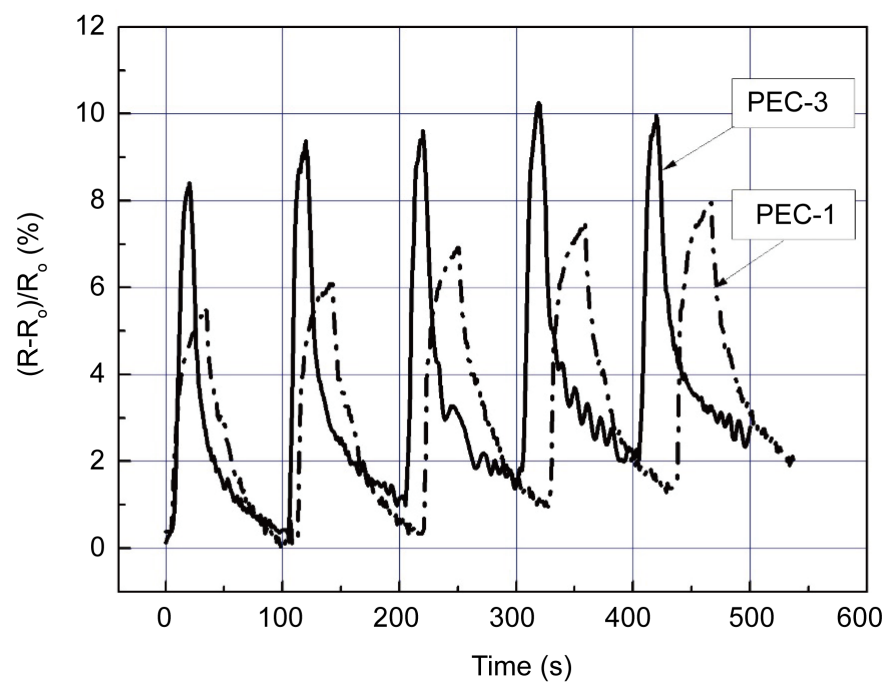

Figure 6. The sensitivity of the PECT-1 and PECT-3 sensor responding to $\mathrm{NH}_{3}$ gas. 
is demonstrated in the J-V characteristics in Figure 5. The PECT-3 sensor showed a quick response and a fast recovery time to $\mathrm{NH}_{3}$ gas. The response is considerably better than the one that was reported as $30 \mathrm{~s}$ in [28] and $32 \mathrm{~s}$ in [29] where the $\mathrm{NH}_{3}$ gas sensors were made from Ag/PEDOT:PSS and Ag/polypyrrole nano-composites, respectively.

\section{Conclusions}

Using spin-coating technique, films of PEDOT-PSS embedded with $\mathrm{TiO}_{2}$-nanoparticles were prepared. The surface morphology, UV-Vis spectra and gas sensing of $\mathrm{NH}_{3}$ were characterized. The results obtained showed that $9.0 \mathrm{wt} \%$ of $\mathrm{nc}-\mathrm{TiO}_{2}$ was the most suitable concentration that was embedded in PEDOT:PSS for hole transport layer as well as for $\mathrm{NH}_{3}$ sensing. The responding time of the sensor made from PEDOT:PSS+nc- $\mathrm{TiO}_{2}$ (with $9.0 \mathrm{wt} \%$ ) possessed a value as fast as $20 \mathrm{~s}$ that is much better than the response of the $\mathrm{NH}_{3}$ gas sensor made from $\mathrm{Ag}$ /polypyrrole nano-composites. The rapid responsiveness to $\mathrm{NH}_{3}$ gas was attributed to the efficient movement of the holes as major charge carriers in PEDOT:PSS +nc- $\mathrm{TiO}_{2}$ composite films.

The obtained results suggest a useful application in monitoring $\mathrm{NH}_{3}$ gas in a polluted environment with a concentration of less than $100 \mathrm{ppm}$. For further works, to enhance both the sensitivity and selectivity of the gases in a range of few parts per million, PEDOT:PSS films incorporated with other additives like carbon nanotubes and graphene quantum dots will be synthesised.

\section{Acknowledgements}

One of the authors (L. M. Long) expresses his sincere thanks to University of Engineering and Technology (VNU Hanoi) and University of Science, VNU Ho Chi Minh city for the support in sample fabrication and experimental measurements.

\section{References}

[1] Quyang, J., Xu, Q., Chu, C.-W., Yang, Y., Li, G. and Shinar, J. (2004) On the Mechanism of Conductivity Enhancement in poly(3,4,ethylenedioxythiophene): Poly(styrene sulfonate) Film through Solvent Treatment. Polymer, 45, 8443-8450.

[2] Tehrani, P., Kanciurzewska, A., Crispin, X., Robinson, N.D., Fahlman, M. and Berggren, M. (2007) The Effect of $\mathrm{pH}$ on the Electrochemical over, Oxidation in Pedot: PSS Films. Solid State Ionics, 177, 3521-3529.

[3] Ouyang, J., Chu, C.-W., Chen, F.-C., Xu, Q. and Yang, Y. (2005) High-Conductivity Poly(3,4-ethylenedioxythiophene): Poly(styrene sulfonate) Film and Its Application in Polymer Optoelectronic Devices. Advanced Functional Materials, 15, 2003-2008. https://doi.org/10.1002/adfm.200400016

[4] Hokazono, M., Anno, H. and Toshima, N. (2014) Thermoelectric Properties and Thermal Stability of PEDOT: PSS Films on a Polyimide Substrate and Application in Flexible Energy Conversion Devices. Journal of Electronic Materials, 3, 21962201. 
[5] Spanggaard, H. and Kerbs, F.C. (2004) A Brief History of the Development of Organic and Polymeric Photovoltaics. Solar Energy Materials and Solar Cells, 83, 125146.

[6] Petrella, A., Tamborra, M., Cozzoli, P.D., Curri, M.L., Striccoli, M., Cosma, P., Farinola, G.M., Babudri, F., Naso, F. and Agostiano, A. (2004) $\mathrm{TiO}_{2}$ NanocrystalsMEH-PPV Composite Thin Films as Photoactive Material. Thin Solid Films, 451452, 64-68.

[7] Burlakov, V.M., Kawata, K., Assender, H.E., Briggs, G.A.D., Ruseckas, A. and Samuel, I.D.W. (2005) Discrete Hopping Model of Exciton Transport in Disordered Media. Physical Review B, 72, Article ID: 075206.

[8] Heuer, H.W., Wehrmann, R. and Kirchmeyer, S. (2002) Electrochromic Window Based on Conducting Poly(3,4-ethylenedioxythiophene)-Poly(styrenesulfonate). Advanced Functional Materials, 12, 89-94. https://doi.org/10.1002/1616-3028(20020201)12:2<89::AID-ADFM89>3.0.CO;2-1

[9] Gavgani, J.N., Dehsari, H.S., Hasani, A., Mahyari, M., Shalamzari, E.K., Salehi, A. and Taromi, F.A. (2015) A Room Temperature Volatile Organic Compound Sensor with Enhanced Performance, Fast Response and Recovery Based on N-Doped Graphene Quantum Dots and Poly(3,4-ethylenedioxythiophene)-poly(styrenesulfonate) Nanocomposite. Royal Society of Chemistry, 5, 57559-57567. https://doi.org/10.1039/C5RA08158K

[10] Olenych, I.B., Aksimentyeva, O.I., Monastyrskii, L.S., Horbenko, Y.Y. and Yarytska, L.I. (2015) Sensory Properties of Hybrid Composites Based on Poly(3,4-ethylenedioxythiophene)-porous Silicon-Carbon Nanotubes. Nanoscale Research Letters, 10, 187-195. https://doi.org/10.1186/s11671-015-0896-1

[11] Basu, S. and Bhattacharyya, P. (2012) Recent Development on Graphene and Graphene Oxide Based Solid State Gas Sensors. Sensors and Actuators B, 173, 1-21.

[12] Yin, P.T., Kim, T.H., Choi, J.W. and Lee, K.B. (2013) Prospects for Graphene-Nanoparticle-Based Hibryd Sensors. Physical Chemistry Chemical Physics, 15, 12785-12799. https://doi.org/10.1039/c3cp51901e

[13] Chu, B.H., Nicolosi, J., Lo, C.F., Strupinski, W., Pearton, S.J. and Ren, F. (2011) Effect of Coated Platinum Thickness on Hydrogen Detection Sensitivity of GrapheneBased Sensors. Electrochemical and Solid State Letters, 14, K43-K46. https://doi.org/10.1149/1.3589250

[14] Zhang, M. and Wang, Z. (2013) Nanostructured Silver Nanowires-Graphene Hybrids for Enhanced Electrochemical Detection of Hydrogen Peroxide. Applied Physics Letters, 102, 213104-213106. https://doi.org/10.1063/1.4807921

[15] Xing, W., Hu, J., Kung, S.-C., Donavan, K.C., Yan, W., Wu, R. and Penner, R.M. (2012) A Chemically-Responsive Nanojunction within a Silver Nanowire. Nano Letters, 12, 1729-1735. https://doi.org/10.1021/nl300427w

[16] Dinh, N.N., Chung, D.N., Thao, T.T. and Hui, D. (2012) Study of Nanostructured Polymeric Composites Used for Organic Light Emitting Diodes and Organic Solar Cells. Journal of Nanomaterials, 2012, Article ID: 190290.

[17] Selvaganesh, S.V., Mathiyarasu, J., Phani, K.L.N. and Yegnaraman, V. (2011) Chemical Synthesis of PEDOT-Au Nanocomposite. Nano Scale Research Letters, 2, 546-549.

[18] Chipara, M. and Chipara, M.D. (2008) Uv-Vis Investigations on Ion Beam Irradiated Polycarbonate. E-Polymers, Article No. 145.

https://doi.org/10.1515/epoly.2008.8.1.1669

[19] Groenendaal, L., Jonas, F., Freitag, D., Pielartzik, H. and Reynolds, J.R. (2000) Poly(3,4-ethylenedioxythiophene) and Its Derivatives: Past, Present, and Future. 
Advanced Materials, 12, 481-494. https://doi.org/10.1002/(SICI)1521-4095(200004)12:7<481::AID-ADMA481>3.0.C $\underline{\mathrm{O} ; 2-\mathrm{C}}$

[20] Dinh, N.N., Chi, L.H., Thuy, T.T.C., Thanh, D.V. and Nguyen, T.P. (2008) Study of Nanostructured Polymeric Composites and Hybrid Layers Used for light Emitting Diodes. Journal of the Korean Physical Society, 53, 802-805. https://doi.org/10.3938/jkps.53.802

[21] Yang, S.H., Nguyen, T.P., Le Rendu, P. and Hsu, C.S. (2005) Optical and Electrical Investigations of Poly(p-phenylene vinylene)/Silicon Oxide and Poly(p-phenylene vinylene)/Titanium Oxide Nanocomposites. Thin Solid Films, 471, 230-235.

[22] Liu, J., Pathak, S., Stergiopoulos, T., Leijtens, T., Wojciechowski, K., Schumann, S., Kausch-Busies, N. and Snaith, H.J. (2015) Employing PEDOT as the p-Type Charge Collection Layer in Regular Organic-Inorganic Perovskite Solar Cells. Journal of Physical Chemistry Letters, 6, 1666-1673. https://doi.org/10.1021/acs.jpclett.5b00545

[23] Dinh, N.N., Chi, L.H., Thuy, T.T.C., Trung, T.Q. and Truong, V.-V. (2009) Enhancement of Current-Voltage Characteristics of Multilayer Organic Light Emitting Diodes by Using Nanostructured Composite Films. Journal of Applied Physics, 105, Article ID: 093518.

[24] Elschner, A., Bruder, F., Heuer, H.-W., Jonas, F., Karbach, A., Kirchmeyer, S., Thurm, S. and Wehrmann, R. (2000) PEDT/PSS for Efficient Hole-Injection in Hybrid Organic Light-Emitting Diodes. Synthetic Metals, 111-112, 139-143.

[25] Book, K., Bässler, H., Elschner, A. and Kirchmeyer, S. (2003) Hole Injection from an ITO/PEDT Anode into the Hole Transporting Layer of an OLED Probed by Bias Induced Absorption. Organic Electronics, 4, 227-232.

[26] Ha, Y.-G., You, E.-A., Kim, B.-J. and Choi, J.-H. (2005) Fabrication and Characterization of OLEDs Using MEH-PPV and SWCNT Nanocomposites. Synthetic Metals, 153, 205-208.

[27] Baldo, M.A. and Forrest, S.R. (2001) Interface-Limited Injection in Amorphous Organic Semiconductors. Physical Review B, 64, Article ID: 085201.

[28] Long, L.M., Dinh, N.N., Thu, H.T., Hoa, H.T.M. and Trung, T.Q. (2016) Synthesis and Characterization of Ag/PEDOT: PSS Films Used for $\mathrm{NH}_{3}$ Selective Sensing. Communications in Physics, 26, 173-180.

[29] Kate, K.H., Shubhangi, R., Damkale, Khanna, P.K. and Jain, G.H. (2011) Nano-Silver Mediated Polymerization of Pyrrole: Synthesis and Gas Sensing Properties of Polypyrrole (PPy)/Ag Nano-Composite. Journal of Nanoscience and Nanotechnology, 11, 7863-7869. 
Submit or recommend next manuscript to SCIRP and we will provide best service for you:

Accepting pre-submission inquiries through Email, Facebook, LinkedIn, Twitter, etc. A wide selection of journals (inclusive of 9 subjects, more than 200 journals)

Providing 24-hour high-quality service

User-friendly online submission system

Fair and swift peer-review system

Efficient typesetting and proofreading procedure

Display of the result of downloads and visits, as well as the number of cited articles Maximum dissemination of your research work

Submit your manuscript at: http://papersubmission.scirp.org/

Or contact msa@scirp.org 